\title{
Effect of Heat Treatment or Alkali Treatment of Veneers on the Mechanical Properties of Eucalyptus Veneer/Polyethylene Film Plywood Composites
}

\author{
Wei Song, ${ }^{\text {a,b,c }}$ Wenbang Wei, ${ }^{\text {a }}$ Congrong Ren, ${ }^{\mathrm{a}}$ and Shuangbao Zhang ${ }^{\mathrm{a}, \mathrm{b}, \mathrm{c}, *}$ \\ New plywood composites for furniture and interior decoration were \\ developed with eucalyptus veneers using polyethylene films as \\ formaldehyde-free adhesives. To enhance the interfacial adhesion, the \\ veneers were modified with an oven treatment (temperature: 100, 120, \\ 140 , and $160{ }^{\circ} \mathrm{C}$; time: $0.5,1.0,1.5$, and $2.0 \mathrm{~h}$ ) or by soaking in a sodium \\ hydroxide $(\mathrm{NaOH})$ solution (concentration: $3 \%, 7 \%$, and $11 \%$; time: 12,24 , \\ and $36 \mathrm{~h}$ ). The effects of these treatments on the mechanical properties \\ (flexural strength, MOR; flexural modulus, MOE; wet shear strength, WSS) \\ of the composites were studied. Both treatments improved the three \\ properties of the composites. The heat treatment was better at improving \\ the shear property, while the alkali treatment was better at improving the \\ flexural properties. For the heat treatment, the highest WSS was $81.1 \%$ \\ higher than the untreated group. The optimum conditions for the heat \\ treatment were $140{ }^{\circ} \mathrm{C}$ and $1.0 \mathrm{~h}$. For the alkali treatment, the highest \\ MOR and MOE were $267.5 \%$ and $173.7 \%$ higher than the untreated group, \\ respectively. The optimum conditions for the alkali treatment were $3 \%$ and \\ $36 \mathrm{~h}$. The changes to the veneer surfaces were determined by scanning \\ electron microscopy.
}

Keywords: Plywood composites; Formaldehyde emission; Formaldehyde-free adhesives; High-density polyethylene films; Interface compatibility; Heat treatment; Alkali treatment; Sodium hydroxide (NaOH); Mechanical properties

Contact information: a: Beijing Key Laboratory of Wood Science and Engineering, Beijing Forestry University, Beijing 100083, China; b: MOE Key Laboratory of Wooden Material Science and Application, Beijing Forestry University, Beijing 100083, China; c: MOE Engineering Research Center of Forestry Biomass Materials and Bioenergy, Beijing Forestry University, Beijing 100083, China;

*Corresponding author: shuangbaozhangj5@163.com

\section{INTRODUCTION}

As one of the most important wood-based composites, plywood manufactured with wood veneers and adhesives has many advantages, such as high strength and light weight (Fang et al. 2013a; Chang et al. 2016). Plywood has been extensively used in various products, including furniture panels, door and window frames, floors, and interior components of automobiles (Fang et al. 2013a; Song et al. 2016; Xu et al. 2016). As an essential component of wood-based composites, the wood adhesives used in plywood are mainly formaldehyde-based, such as urea-formaldehyde resins (Chang et al. 2017). Although these adhesives have merits, such as good adhesive force, and are a mature technology, they usually lead to high formaldehyde emissions during the fabrication and usage of plywood, which is mainly caused by some unreacted formaldehyde remaining in the resins and the low hydrolysis resistance of the resins (Fang et al. 2013a; Yu et al. 2015; Song et al. 2017a). Because formaldehyde is a human carcinogen, this emission poses a 
great hazard to the environment and human health (Song et al. 2015a). As a result, there is an urgent need to develop formaldehyde-free wood adhesives and environmentally friendly plywood (Fang et al. 2013b; Qi et al. 2016; Di et al. 2017).

As one of the most widely used packaging materials, plastic films have been used as formaldehyde-free adhesives for fabricating plywood because they are inexpensive, relatively tough, and possess good dimensional stability when exposed to moisture (Fang et al. 2013b). Thus, they offer many technological and environmental benefits when used as a wood adhesive (Fang et al. 2013b). Compared with conventional plywood bonded with urea-formaldehyde resins, the plywood bonded with plastic films has been found to exhibit several merits, such as a relatively high flexural strength, low thickness swelling and water absorption, and most importantly, environmental superiority (Fang et al. 2014). Recently, Fang et al. (2013a, b) evaluated the physical, mechanical, and thermal properties of plywood bonded with high-density polyethylene (HDPE) films. Chang et al. (2016) and Chang et al. (2017) investigated the hot-pressing conditions and bonding mechanism of plywood bonded with HDPE films. Song et al. (2016; 2017a) compared the physicalmechanical properties of plywood that used polypropylene films, polyethylene films, ureaformaldehyde resins, and phenol-formaldehyde resins as adhesives. Song et al. (2017b) studied the preparation and properties of plywood bonded with polyvinyl chloride films.

However, the usually hydrophilic wood and natural fibers have inherently low compatibility with hydrophobic plastic, especially polyolefin plastics such as polypropylene and polyethylene (Fang et al. 2014; Song et al. 2015b). The low compatibility between wood and plastic may result in an insufficient wetting of the plastic films on the veneer surfaces, which leads to poor interfacial adhesion between the two phases and adversely affects various properties of the plastic film-bonded plywood, and limits their applications (Fang et al. 2014). In order to enhance the interfacial adhesion of plywood bonded with plastic films, surface modification methods for wood veneers have been studied, such as a coupling agent treatment for veneer surfaces. For example, Fang et al. $(2014 ; 2016 \mathrm{a}, \mathrm{b}, \mathrm{c})$ used vinyltrimethoxysilane-treated veneers to prepare HDPE filmbonded plywood. Song et al. (2017) used $\gamma$-aminopropyltriethoxysilane-treated veneers and maleic anhydride grafted polypropylene-treated veneers to prepare polypropylene film-bonded plywood. Song et al. (2017b) used $\gamma$-aminopropyltriethoxysilane-treated veneers to prepare polyvinyl chloride film-bonded plywood.

Heat treatment is one of the oldest and most environmentally-friendly wood modification procedures (Chu et al. 2016). From the literature, the minimum temperature necessary to perform a heat treatment is $100{ }^{\circ} \mathrm{C}$ (Esteves and Pereira 2009), while the treatment time ranges from $15 \mathrm{~min}$ to $24 \mathrm{~h}$ (Chu et al. 2016). Without using chemicals, heat treatment increases the water contact angles of the wood and decreases the hydroscopicity, while also enhancing the dimensional stability and biodegradation resistance (Ding et al. 2015; Zhan et al. 2015; Ding et al. 2016; Zhang et al. 2017). Considering these advantages, heat treatment has been employed in the preparation of natural fiber composites and the effects have been studied. For example, the thermal decomposition, water absorption, and nonisothermal crystallization properties of heat-treated bamboo fiber/HDPE composites were studied by Li et al. (2013), Du et al. (2014), and Li et al. (2015), respectively. Tufan et al. (2016) investigated the technological and thermal properties of heat-treated alder wood flour/HDPE composites. Ahamad Nordin et al. (2017) examined the mechanical, morphology, thermal, and water adsorption properties of heat-treated oil palm mesocarp fiber/polypropylene composites. Although heat treatment can also be used to treat wood veneers, its effects on plastic film-bonded plywood have rarely been reported on. 
Alkali treatment is one of the simplest, most economical, and most effective surface modification methods for natural fibers with the low environmental impact (Then et al. 2015). For alkali treatments, sodium hydroxide $(\mathrm{NaOH})$ aqueous solution is preferred because of the low cost, but ammonia hydroxide $\left(\mathrm{NH}_{3} \cdot \mathrm{H}_{2} \mathrm{O}\right)$ solution has also been used in some studies (Then et al. 2015; Cao et al. 2017). From the literature, the $\mathrm{NaOH}$ treatments at room temperature have been performed with an alkali concentration ranging from $1.0 \%$ to $17.5 \%$ and treatment times ranging from $20 \mathrm{~min}$ to $672 \mathrm{~h}$ (Ray et al. 2009; Elenga et al. 2013). Typically, an alkali treatment decreases the hydrophilicity of the fibers, which reduces particle agglomeration (Daud et al. 2017). Moreover, this treatment increases the surface roughness of the fibers, which results in efficient contact with the polymers when preparing composites (Lazim et al. 2014; Lu et al. 2014). Because of these advantages, alkali treatments have been used in the manufacture of natural fiber composites (Ndazi et al. 2008). For example, Kalagar et al. (2011) examined the morphology and mechanical properties of alkali-treated rice straw flour/polypropylene composites. Gao et al. (2014) studied the mechanical properties of alkali-treated kraft fiber/unsaturated polyester composites. Then et al. (2015) investigated the static mechanical, interfacial, and water absorption behaviors of alkali-treated oil palm mesocarp fiber/poly(butylene succinate) composites. Although an alkali treatment can also be used to treat wood veneers, its effects on plastic film-bonded plywood are still unknown.

In this research, plywood composites were prepared with eucalyptus veneers using HDPE films as the formaldehyde-free adhesive. To enhance the interfacial adhesion, the veneers were modified using a heat or alkali treatment. During the heat treatment, the treatment temperature $\left(100\right.$ to $\left.160{ }^{\circ} \mathrm{C}\right)$ and time $(0.5$ to $2.0 \mathrm{~h})$ were independent variables. For the alkali treatment, the alkali concentration (3\% to 11\%) and treatment time (12 to 36 h) were independent variables. In this paper, the effect of these independent variables on the mechanical properties of the plywood composites was studied in order to gather useful information for the development of plastic film-bonded plywood composites.

\section{EXPERIMENTAL}

\section{Materials}

Wood veneers (species: Eucalyptus grandis $\times$ E. urophylla; dimensions, $400 \times 400$ $\times 2 \mathrm{~mm}^{3}$; moisture content, $8 \%$ ) were purchased from a plantation in Liuzhou, Guangxi Region, China. The HDPE films (thickness, $0.06 \mathrm{~mm}$; area density of one layer, $60 \mathrm{~g} / \mathrm{m}^{2}$ ) were purchased from Huadun Snowflake Plastics Group Co. Ltd. (Beijing, China). The $\mathrm{NaOH}$ powder was purchased from Beijing Chemical Works (Beijing, China).

\section{Heat Treatment of the Veneers}

During the heat treatment, the veneers were treated in a laboratory oven (Table 1). The two independent variables of the heat treatment were the treatment temperature (100, 120,140 , and $\left.160^{\circ} \mathrm{C}\right)$ and time $(0.5,1.0,1.5$, and $2.0 \mathrm{~h})$, which resulted in 16 treated groups (H1 to H16). After the heat treatment, the veneers were naturally cooled to room temperature.

\section{Alkali Treatment of the Veneers}

For the alkali treatment, the veneers were soaked in a $\mathrm{NaOH}$ aqueous solution at room temperature. As shown in Table 2, the two independent variables of the alkali 
treatment were the alkali concentration (the mass fraction of the solution; $3 \%, 7 \%$, and $11 \%$ ) and treatment time $(12,24$, and $36 \mathrm{~h}$ ), which resulted in nine treated groups (A1 to A9). After the alkali treatment, the veneers were washed with water to remove the residual $\mathrm{NaOH}$, air-dried for $4 \mathrm{~h}$, and then oven-dried for $4 \mathrm{~h}$.

Table 1. Independent Variables and Group Numbers of the Heat Treatment

\begin{tabular}{|c|c|c|c|c|}
\hline \multirow{2}{*}{ Time $(\mathrm{h})$} & \multicolumn{4}{|c|}{ Temperature $\left({ }^{\circ} \mathrm{C}\right)$} \\
\cline { 2 - 5 } & 100 & 120 & 140 & 160 \\
\hline 0.5 & $\mathrm{H} 1$ & $\mathrm{H} 5$ & $\mathrm{H} 9$ & $\mathrm{H} 13$ \\
\hline 1.0 & $\mathrm{H} 2$ & $\mathrm{H} 6$ & $\mathrm{H} 10$ & $\mathrm{H} 14$ \\
\hline 1.5 & $\mathrm{H} 3$ & $\mathrm{H} 7$ & $\mathrm{H} 11$ & $\mathrm{H} 15$ \\
\hline 2.0 & $\mathrm{H} 4$ & $\mathrm{H} 8$ & $\mathrm{H} 12$ & $\mathrm{H} 16$ \\
\hline
\end{tabular}

Table 2. Independent Variables and Group Numbers of the Alkali Treatment

\begin{tabular}{|c|c|c|c|}
\hline \multirow{2}{*}{ Time $(\mathrm{h})$} & \multicolumn{3}{|c|}{ Alkali Concentration (\%) } \\
\cline { 2 - 4 } & 3 & 7 & 11 \\
\hline 12 & A1 & A4 & A7 \\
\hline 24 & A2 & A5 \\
\hline 36 & A3 & A6 & A9 \\
\hline
\end{tabular}

\section{Preparation of the Plywood Composites}

Three-layer plywood composites were manufactured. The plywood was prepared with opposing tight-side and loose-side veneers in all the glue lines, and was stacked with the grain directions of the two adjacent veneers perpendicular to each other (Fang et al. 2014). Between every two veneers, two layers of HDPE films were added as adhesive with a dosage of $120 \mathrm{~g} / \mathrm{m}^{2}$. The composites were hot-pressed at $160{ }^{\circ} \mathrm{C}$ for $5 \mathrm{~min}$ under a pressure of $0.7 \mathrm{MPa}$, then cold-pressed at room temperature for $5 \mathrm{~min}$ under a pressure of 1.0 MPa. More details about the preparation of the plastic film-bonded plywood composites, such as the selection of the hot-pressing temperature, can be found in our previous reports (Song et al. 2016; 2017).

\section{Mechanical Analysis of the Composites}

The flexural strength (MOR), flexural modulus (MOE), and wet shear strength (WSS) of the composites were measured according to the Chinese national standard GB/T 9846 (2015). The MOR and MOE were measured using a three-point flexural test. The WSS was measured after the composites were soaked in $63{ }^{\circ} \mathrm{C}$ water for $3 \mathrm{~h}$. The measurements were repeated six times. The mechanical measurements were performed using an MWW-50 universal mechanical testing machine (Tayasaf Corporation, Beijing, China).

\section{Scanning Electron Microscopy (SEM) Analysis of the Veneer Surfaces}

The scanning electron microscopy (SEM) images of the untreated, heat-treated (H16), and alkali-treated (A9) veneer surfaces were taken by an S-3400N scanning electron microscope (Hitachi, Tokyo, Japan) with an acceleration voltage of $5 \mathrm{kV}$. Prior to observation, the samples were sputter-coated with gold. 


\section{RESULTS AND DISCUSSION}

\section{Effects of the Heat Treatment on the Mechanical Properties of the Composites}

Effect of the heat treatment on the MOR of the composites

Table 3 shows the MOR of the composites made from the heat-treated veneers. As shown, the MOR values of the treated groups were all higher than the untreated group. The average MOR of the treated groups was $58.7 \mathrm{MPa}$, which was $38.6 \%$ higher than the untreated group.

Table 3. MOR (MPa) of the Heat-Treated Composites ( $\mathrm{H} 1$ to $\mathrm{H} 16)$

\begin{tabular}{|c|c|c|c|c|c|}
\hline \multirow{2}{*}{$\begin{array}{c}\text { Treatment } \\
\text { Time }(\mathrm{h})\end{array}$} & 100 & 120 & 140 & 160 & \multirow{2}{*}{ Average } \\
\cline { 2 - 5 } 0.5 & 53.47 & 58.52 & 63.89 & 67.20 & 60.77 \\
& $(3.05)$ & $(5.51)$ & $(1.90)$ & $(4.03)$ & $(6.04)$ \\
\hline \multirow{2}{*}{1.0} & 59.18 & 58.81 & 55.33 & 64.79 & 59.53 \\
& $(3.89)$ & $(1.54)$ & $(1.37)$ & $(3.34)$ & $(3.91)$ \\
\hline \multirow{2}{*}{1.5} & 49.48 & 70.15 & 56.75 & 48.76 & 56.29 \\
& $(2.06)$ & $(2.96)$ & $(3.00)$ & $(1.73)$ & $(9.92)$ \\
\hline \multirow{2}{*}{2.0} & 53.41 & 69.75 & 54.16 & 55.23 & 58.14 \\
& $(3.93)$ & $(5.87)$ & $(1.64)$ & $(2.87)$ & $(7.78)$ \\
\hline \multirow{2}{*}{ Average } & 53.89 & 64.31 & 57.53 & 59.00 & 58.68 \\
& $(3.99)$ & $(6.52)$ & $(4.37)$ & $(8.56)$ & $(6.72)$ \\
\hline
\end{tabular}

When the treatment temperature ranged from 100 to $160{ }^{\circ} \mathrm{C}$, the average MOR ranged from 53.9 to $64.3 \mathrm{MPa}$, which caused a coefficient of variance of $7.4 \%$. The average MOR values of the $100,120,140$, and $160^{\circ} \mathrm{C}$ groups were all higher than the untreated group. The highest average MOR was $64.31 \mathrm{MPa}$ for the $120{ }^{\circ} \mathrm{C}$ group, which was $51.8 \%$ higher than the untreated group.

When the treatment time ranged from 0.5 to $2.0 \mathrm{~h}$, the average MOR ranged from 56.3 to $60.8 \mathrm{MPa}$, which caused a coefficient of variance of $3.3 \%$. The average MOR values of the 0.5-, 1.0-, 1.5-, and 2.0-h groups were all higher than the untreated group. The highest average MOR was $60.8 \mathrm{MPa}$ for the 0.5 -h group, which was $43.5 \%$ higher than the untreated group.

The results of the coefficient of variance analysis indicated that the treatment temperature had a greater effect on the MOR than the treatment time. The analysis of variance indicated that the effect of the treatment temperature was significant at a 0.05 level, but the effect of the treatment time was insignificant at a 0.05 level. Among the sixteen treated groups, the highest MOR was $70.2 \mathrm{MPa}$ for $\mathrm{H} 7$, which was $65.6 \%$ higher than the untreated group.

\section{Effect of the heat treatment on the MOE of the composites}

Table 4 shows the MOE of the composites made from the heat-treated veneers. The MOE values of the treated groups were all higher than the untreated group, except for H12. The average MOE of the treated groups was $8.77 \mathrm{GPa}$, which was $34.3 \%$ higher than the untreated group. 
Table 4. MOE (GPa) of the Heat-Treated Composites ( $\mathrm{H} 1$ to $\mathrm{H} 16)$

\begin{tabular}{|c|c|c|c|c|c|}
\hline \multirow{2}{*}{$\begin{array}{c}\text { Treatment } \\
\text { Time }(\mathrm{h})\end{array}$} & \multicolumn{4}{|c|}{ Treatment Temperature $\left({ }^{\circ} \mathrm{C}\right)$} & \multirow{2}{*}{ Average } \\
\hline & 100 & 120 & 140 & 160 & \\
\hline 0.5 & $\begin{array}{c}7.55 \\
(0.59)\end{array}$ & $\begin{array}{c}8.43 \\
(0.35)\end{array}$ & $\begin{array}{l}10.83 \\
(0.96)\end{array}$ & $\begin{array}{l}10.39 \\
(0.37)\end{array}$ & $\begin{array}{c}9.30 \\
(1.57)\end{array}$ \\
\hline 1.0 & $\begin{array}{c}9.42 \\
(0.70)\end{array}$ & $\begin{array}{c}8.54 \\
(0.18)\end{array}$ & $\begin{array}{c}9.61 \\
(0.64)\end{array}$ & $\begin{array}{c}8.68 \\
(0.79)\end{array}$ & $\begin{array}{c}9.06 \\
(0.53)\end{array}$ \\
\hline 1.5 & $\begin{array}{c}9.34 \\
(0.45)\end{array}$ & $\begin{array}{c}9.38 \\
(0.45)\end{array}$ & $\begin{array}{c}8.85 \\
(0.35) \\
\end{array}$ & $\begin{array}{c}8.52 \\
(0.56)\end{array}$ & $\begin{array}{c}9.02 \\
(0.41)\end{array}$ \\
\hline 2.0 & $\begin{array}{c}7.91 \\
(0.54)\end{array}$ & $\begin{array}{c}9.47 \\
(0.54)\end{array}$ & $\begin{array}{c}5.46 \\
(0.24)\end{array}$ & $\begin{array}{c}7.98 \\
(0.68)\end{array}$ & $\begin{array}{c}7.71 \\
(1.66)\end{array}$ \\
\hline Average & $\begin{array}{c}8.55 \\
(0.96) \\
\end{array}$ & $\begin{array}{c}8.95 \\
(0.55) \\
\end{array}$ & $\begin{array}{c}8.69 \\
(2.30) \\
\end{array}$ & $\begin{array}{c}8.89 \\
(1.04) \\
\end{array}$ & $\begin{array}{c}8.77 \\
(1.24)\end{array}$ \\
\hline
\end{tabular}

When the treatment temperature ranged from 100 to $160{ }^{\circ} \mathrm{C}$, the average MOE ranged from 8.55 to $8.95 \mathrm{GPa}$, which caused a coefficient of variance of $2.1 \%$. The average MOE values of the $100,120,140$, and $160{ }^{\circ} \mathrm{C}$ groups were all higher than the untreated group. The highest average MOE was $8.95 \mathrm{GPa}$ for the $120{ }^{\circ} \mathrm{C}$ group, which was $37.10 \%$ higher than the untreated group.

When the treatment time ranged from 0.5 to $2.0 \mathrm{~h}$, the average MOE ranged from 7.71 to $9.30 \mathrm{GPa}$, which caused a coefficient of variance of $8.2 \%$. The average MOE values of the 0.5-, 1.0-, 1.5-, and 2.0-h groups were all higher than the untreated group. The highest average MOE was $9.30 \mathrm{GPa}$ for the 0.5 -h group, which was $42.4 \%$ higher than the untreated group.

The results of the coefficient of variance analysis indicated that the treatment time had a greater effect on the MOE than the treatment temperature. The analysis of variance indicated that the effect of the treatment temperature was insignificant at a 0.05 level, but the effect of the treatment time was significant at a 0.05 level. Among the sixteen treated groups, the highest MOE was $10.83 \mathrm{GPa}$ for $\mathrm{H} 9$, which was $65.8 \%$ higher than the untreated group.

\section{Effect of the heat treatment on the WSS of the composites}

Table 5 shows the WSS of the composites made from the heat-treated veneers. The WSS values of the treated groups were all higher than the untreated group, except for H13 and H16. The average WSS of the treated groups was $0.93 \mathrm{MPa}$, which was $26.3 \%$ higher than the untreated group.

When the treatment temperature ranged from 100 to $160{ }^{\circ} \mathrm{C}$, the average WSS ranged from 0.78 to $1.17 \mathrm{MPa}$, which caused a coefficient of variance of $18.8 \%$. The average WSS values of the $100,120,140$, and $160{ }^{\circ} \mathrm{C}$ groups were all higher than the untreated group. The highest average WSS was $1.17 \mathrm{MPa}$ for the $140{ }^{\circ} \mathrm{C}$ group, which was $58.4 \%$ higher than the untreated group.

When the treatment time ranged from 0.5 to $2.0 \mathrm{~h}$, the average WSS ranged from 0.87 to $1.03 \mathrm{MPa}$, which caused a coefficient of variance of $7.0 \%$. The average WSS values of the 0.5-, 1.0-, 1.5-, and 2.0-h groups were all higher than the untreated group. The highest average WSS was $1.03 \mathrm{MPa}$ for the 1.0-h group, which was $38.8 \%$ higher than the untreated group. 
Table 5. WSS (MPa) of the Heat-Treated Composites ( $\mathrm{H} 1$ to $\mathrm{H} 16)$

\begin{tabular}{|c|c|c|c|c|c|}
\hline \multirow{2}{*}{$\begin{array}{c}\text { Treatment } \\
\text { Time }(\mathrm{h})\end{array}$} & 100 & 120 & 140 & 160 & \multirow{2}{*}{ Average } \\
\cline { 2 - 5 } 0.5 & 0.84 & 1.11 & 1.09 & 0.62 & 0.92 \\
& $(0.05)$ & $(0.04)$ & $(0.04)$ & $(0.06)$ & $(0.23)$ \\
\hline \multirow{2}{*}{1.0} & 0.90 & 0.93 & 1.34 & 0.94 & 1.03 \\
& $(0.08)$ & $(0.05)$ & $(0.08)$ & $(0.06)$ & $(0.21)$ \\
\hline \multirow{2}{*}{1.5} & 0.77 & 0.97 & 0.92 & 0.83 & 0.87 \\
& $(0.03)$ & $(0.08)$ & $(0.07)$ & $(0.02)$ & $(0.09)$ \\
\hline \multirow{2}{*}{2.0} & 0.83 & 0.81 & 1.34 & 0.71 & 0.92 \\
& $(0.06)$ & $(0.02)$ & $(0.09)$ & $(0.04)$ & $(0.28)$ \\
\hline \multirow{2}{*}{ Average } & 0.84 & 0.96 & 1.17 & 0.78 & 0.93 \\
& $(0.05)$ & $(0.12)$ & $(0.21)$ & $(0.14)$ & $(0.20)$ \\
\hline
\end{tabular}

The results of the coefficient of variance analysis indicated that the treatment temperature had a greater effect on the WSS than the treatment time. The analysis of variance indicated that the effects of the treatment temperature and the treatment time were both significant at a 0.05 level. Among the sixteen treated groups, the highest WSS was 1.34 MPa for $\mathrm{H} 10$ and $\mathrm{H} 12$, which was $81.1 \%$ higher than the untreated group.

\section{Discussion of the effects of the heat treatment on the wood and composites}

Heat treatment of wood changes its chemical composition by degrading cell wall compounds, such as hemicellulose, cellulose, and lignin. For example, hemicellulose is the most hydrophilic cell wall component that is thermally unstable (Ahamad Nordin et al. 2017). The degradation of hemicellulose begins with deacetylation, and the emitted acetic acid serves as a depolymerization catalyst, which further promotes polysaccharide decomposition; meanwhile, hemicellulose undergoes dehydration reactions with the removal of hydroxyl groups (Ayata et al. 2017). Because of its crystalline nature, cellulose is less affected by heat treatment (Esteves and Pereira 2009). As was reported in the literature, the hydroxyl groups in cellulose degrade in the following order: amorphous, semi-crystalline, and crystalline regions (Esteves and Pereira 2009). The crystallinity of cellulose increases because of the removal of amorphous cellulose, which leads to a decreased accessibility of hydroxyl groups to water molecules and contributes to a decrease in the equilibrium moisture content, in addition to the major effect caused by the removal of hemicellulose (Esteves and Pereira 2009). For lignin, polycondensation reactions occur with other cell wall components, which lead to further cross-linking and contribute to an apparent increase in the lignin content (Ding et al. 2011). Typically, the cleavage of ether linkages, especially $\beta-\mathrm{O}-4$, results in the generation of free phenolic hydroxyl groups and $\alpha$ - and $\beta$-carbonyl groups, which induces cross-linking via the formation of methylenic bridges (Ayata et al. 2017).

The above-mentioned chemical transformations can affect the properties of wood. For example, Chu et al. (2016) studied the surface characteristics of heat-treated poplar wood. It was found that the heat treatment increased the hydrophobicity of the wood surfaces, which was primarily because of the loss of free reactive hydroxyl groups caused by the degradation of hemicellulose, as well as amorphous and semi-crystalline cellulose. During heat treatment, the degradation of cell wall components and vapor pressure led to a more open structure of the wood, such as a distinctly increased size and number of pores, 
stratified microstructures, and some deformation of libriform fibers near the vessels. The cracks around pits and laminarization of cell walls resulted in the embrittlement and mechanical decline of wood surfaces, which also led to a higher surface roughness. Zhang et al. (2017) reported that heat treatment decreased the water uptake ability of larch and red oak. Missio et al. (2016) reported that heat treatment increased the MOE and compression strength of rose gum and Gympie messmate, but decreased the MOR, impact strength, and Janka hardness.

According to the above analysis, the heat treatment of veneers may produce some positive effects on the mechanical properties of the eucalyptus veneer/HDPE film plywood composites. For example, heat treatment could decrease the hydrophilicity of veneer surfaces, which could enhance the compatibility with hydrophobic HDPE films, and thus improve the interfacial adhesion of the composites. Additionally, heat treatment could increase the surface roughness and surface area of veneers, which could improve the chances of interlocking between the veneer surface and HDPE film, and enhance the adhesive bonded joints in the composites. Moreover, a moderate heat treatment could improve the mechanical properties of the wood, such as the MOE, which might be good for the mechanical properties of the composites. In this research, the positive effects from the heat treatment were noticeable. For example, as shown in Tables 3 to 5, the MOR, MOE, and WSS values of most of the treated groups were higher than the untreated group. Similar results were found in previous studies on natural fiber composites. For example, Du et al. (2014) reported that heat treatment of bamboo fiber decreased the moisture diffusion coefficient values of bamboo fiber/HDPE composites. Tufan et al. (2016) reported that heat treatment of alder wood flour decreased the water adsorption of wood flour/HDPE composites, and increased the tensile modulus. Ahamad Nordin et al. (2017) reported that heat treatment of oil palm mesocarp fibers decreased the water absorption of palm fiber/polypropylene composites, and increased the flexural strength and modulus, tensile strength and modulus, and impact strength.

Note that heat treatment may also cause some negative effects on wood properties. For example, the degradation of cell wall components could lead to the deterioration of microstructures, which could decrease the mechanical properties of wood. These results might be not good for the mechanical properties of the eucalyptus veneer/HDPE film plywood composites. In this research, negative effects from the heat treatment were also observed. For example, as shown in Tables 3 to 5, when the treatment time was $1.5 \mathrm{~h}$, the MOR, MOE, and WSS values all decreased when the treatment temperature increased from 120 to $160{ }^{\circ} \mathrm{C}$. Similar results were found in previous studies on natural fiber composites. For example, Tufan et al. (2016) reported that heat treatment of alder wood flour decreased the flexural strength and modulus, and tensile strength of wood flour/HDPE composites.

In this research, both positive and negative effects from the heat treatment on the eucalyptus veneer/HDPE film plywood composites were observed, which indicated that they were two competing factors with complicated interactions. The effect that was dominant depended on the treatment conditions (treatment temperature and time). The optimum conditions for the heat treatment should be the conditions that result in the greatest positive effects. Overall, the general optimum conditions for the MOR, MOE, and WSS were not found, which indicated that the effects from the heat treatment on each property were different. 


\section{Determination of the optimum conditions for the heat treatment}

The optimum conditions for the heat treatment were determined according to the variation ratios of the mechanical data for the treated groups compared with the untreated group. First, the treated groups containing the negative variation ratio were eliminated, because the optimum conditions should not deteriorate the mechanical properties. Then, the treated groups with the higher average variation ratio for the three mechanical properties were selected to be the candidates, because the optimum conditions should cause the better improving effects on the overall mechanical properties. Finally, a candidate with the higher WSS variation ratio was considered to have the optimum conditions, because the optimum conditions should lead to the better improving effects simultaneously on all the three mechanical properties, and the variation ratio results for both the heat and alkali treatments indicated that the WSS was more difficult to be improved, compared with the MOR and MOE.

Table 6 shows the variation ratios of the MOR, MOE, and WSS of H1 to H16 compared with the untreated group. As can be seen, the MOE variation ratio for $\mathrm{H} 12$ and WSS variation ratios for $\mathrm{H} 13$ and $\mathrm{H} 16$ were negative, and thus these groups were not considered to be the optimum conditions for the heat treatment. The average variation ratios for $\mathrm{H} 9$ and $\mathrm{H} 10$ were noticeably higher than the other groups, but the WSS variation ratio for $\mathrm{H} 10$ was clearly higher than $\mathrm{H} 9$. As such, $\mathrm{H} 10$ was determined to be the optimum conditions for the heat treatment.

Table 6. Variation Ratios of the MOR, MOE, and WSS of the Composites

\begin{tabular}{|c|c|c|c|c|}
\hline \multirow{2}{*}{ Group Number } & \multicolumn{4}{|c|}{ Variation Ratio Compared with the Untreated Group (\%) } \\
\cline { 2 - 5 } & MOR & MOE & WSS & Average \\
\hline H1 & 26.26 & 15.62 & 13.51 & 18.46 \\
\hline H2 & 39.74 & 44.18 & 21.62 & 35.18 \\
\hline H3 & 16.84 & 42.96 & 4.05 & 21.28 \\
\hline H4 & 26.12 & 21.08 & 12.16 & 19.79 \\
\hline H5 & 38.18 & 29.02 & 50.00 & 39.07 \\
\hline H6 & 38.87 & 30.73 & 25.68 & 31.76 \\
\hline H7 & 65.64 & 43.64 & 31.08 & 46.79 \\
\hline H8 & 64.70 & 45.02 & 9.46 & 39.73 \\
\hline H9 & 50.86 & 65.82 & 47.30 & 54.66 \\
\hline H10 & 30.65 & 47.12 & 81.08 & 52.95 \\
\hline H11 & 34.00 & 35.48 & 24.32 & 31.27 \\
\hline H12 & 27.89 & -16.39 & 81.08 & 30.86 \\
\hline H13 & 58.68 & 59.14 & -16.22 & 33.87 \\
\hline H14 & 52.99 & 32.95 & 27.03 & 37.65 \\
\hline H15 & 15.14 & 30.45 & 12.16 & 19.25 \\
\hline H16 & 30.41 & 22.26 & -4.05 & 16.21 \\
\hline
\end{tabular}

The heat treatment performed in this research was different from the heat treatment used in Fang et al. (2017). The cited authors treated poplar veneers at $200{ }^{\circ} \mathrm{C}$ for $30 \mathrm{~min}$, and prepared HDPE film-bonded plywood. It was found that heat treatment of the veneers 
enhanced the WSS and water resistance of plywood. However, the treated plywood had $28 \%$ and $21 \%$ lower MOR and MOE values than the untreated plywood, respectively. This indicated that the treatment conditions had remarkably negative effects on the plywood, which was most likely because $200{ }^{\circ} \mathrm{C}$ was too high for the treatment temperature. Similar results were found in other studies. For example, Zhang et al. (2015) studied the physicalmechanical properties of heat-treated Eucalyptus regnans, and found that the nail-holding ability, surface hardness, MOR, and MOE of the wood treated at 120 and $130{ }^{\circ} \mathrm{C}$ increased compared with the untreated wood, but decreased when the wood was treated at 140 to $200{ }^{\circ} \mathrm{C}$. In the present research, the MOR, MOE, and WSS were all improved after the heat treatment, which indicated that the proposed treatment conditions produced greater positive effects on the wood and plywood composites.

\section{Effects of the Alkali Treatment on the Mechanical Properties of the Composites}

Effect of the alkali treatment on the MOR of the composites

Table 7 shows the MOR of the composites made from the alkali-treated veneers. The MOR values of the treated groups were all higher than the untreated group. The average MOR of the treated groups was $104.6 \mathrm{MPa}$, which was $147.1 \%$ higher than the untreated group.

Table 7. MOR (MPa) of the Alkali-Treated Composites (A1 to A9)

\begin{tabular}{|c|c|c|c|c|}
\hline \multirow{2}{*}{$\begin{array}{c}\text { Treatment Time } \\
(\mathrm{h})\end{array}$} & \multicolumn{3}{|c|}{ Alkali Concentration (\%) } & \multirow{2}{*}{ Average } \\
\cline { 2 - 4 } 12 & 3 & 7 & 11 & 78.11 \\
& $(5.03$ & 76.18 & 85.12 & $(6.27)$ \\
\hline \multirow{2}{*}{24} & 148.90 & $(6.02)$ & $(4.05)$ & 113.37 \\
& $(5.53)$ & $(8.82)$ & 89.01 & $(31.47)$ \\
\hline \multirow{2}{*}{36} & 155.64 & 131.90 & $79.59)$ & 122.47 \\
& $(4.22)$ & $(3.49)$ & $(4.46)$ & $(38.75)$ \\
\hline \multirow{2}{*}{ Average } & 125.86 & 103.43 & 84.67 & 104.65 \\
& $(45.87)$ & $(27.88)$ & $(4.58)$ & $(32.32)$ \\
\hline \multicolumn{4}{l}{ The MOR of the untreated group is 42.35 MPa. } \\
\hline
\end{tabular}

When the alkali concentration ranged from $3 \%$ to $11 \%$, the average MOR ranged from 84.7 to $125.9 \mathrm{MPa}$, which caused a coefficient of variance of $19.7 \%$. The average MOR values of the $3 \%, 7 \%$, and $11 \%$ groups were all higher than the untreated group. The highest average MOR was $125.9 \mathrm{MPa}$ for the 3\% group, which was $197.2 \%$ higher than the untreated group.

When the treatment time ranged from 12 to $36 \mathrm{~h}$, the average MOR ranged from 78.1 to $122.5 \mathrm{MPa}$, which caused a coefficient of variance of $22.4 \%$. The average MOR values of the 12-, 24-, and 36-h groups were all higher than the untreated group. The highest average MOR was $122.5 \mathrm{MPa}$ for the 36-h group, which was $189.2 \%$ higher than the untreated group.

The results of the coefficient of variance analysis indicated that the treatment time had a greater effect on the MOR than the alkali concentration. The analysis of variance indicated that the effects of the alkali concentration and the treatment time were both significant at a 0.05 level. Among the nine treated groups, the highest MOR was 155.6 MPa for A3, which was $267.5 \%$ higher than the untreated group. 
Effect of the alkali treatment on the MOE of the composites

Table 8 shows the MOE of the composites made from the alkali-treated veneers. The MOE values of the treated groups were all higher than the untreated group. The average MOE of the treated groups was $14.4 \mathrm{GPa}$, which was $120.8 \%$ higher than the untreated group.

Table 8. MOE (GPa) of the Alkali-Treated Composites (A1 to A9)

\begin{tabular}{|c|c|c|c|c|}
\hline \multirow{2}{*}{$\begin{array}{c}\text { Treatment Time } \\
\text { (h) }\end{array}$} & \multicolumn{3}{|c|}{ Alkali Concentration (\%) } & \multirow{2}{*}{ Average } \\
\hline & 3 & 7 & 11 & \\
\hline 12 & $\begin{array}{l}11.45 \\
(0.76)\end{array}$ & $\begin{array}{l}11.24 \\
(0.99)\end{array}$ & $\begin{array}{l}13.34 \\
(1.06)\end{array}$ & $\begin{array}{l}12.01 \\
(1.16)\end{array}$ \\
\hline 24 & $\begin{array}{l}17.78 \\
(1.76)\end{array}$ & $\begin{array}{l}17.50 \\
(0.93)\end{array}$ & $\begin{array}{l}13.47 \\
(0.67)\end{array}$ & $\begin{array}{l}16.25 \\
(2.41)\end{array}$ \\
\hline 36 & $\begin{array}{l}17.88 \\
(0.73)\end{array}$ & $\begin{array}{l}15.17 \\
(0.65)\end{array}$ & $\begin{array}{l}11.93 \\
(0.37)\end{array}$ & $\begin{array}{l}14.99 \\
(2.98)\end{array}$ \\
\hline Average & $\begin{array}{l}15.70 \\
(3.69)\end{array}$ & $\begin{array}{l}14.64 \\
(3.17)\end{array}$ & $\begin{array}{l}12.92 \\
(0.85)\end{array}$ & $\begin{array}{l}14.42 \\
(2.75)\end{array}$ \\
\hline
\end{tabular}

When the alkali concentration ranged from $3 \%$ to $11 \%$, the average MOE ranged from 12.9 to $15.7 \mathrm{GPa}$, which caused a coefficient of variance of $9.8 \%$. The average MOE values of the $3 \%, 7 \%$, and $11 \%$ groups were all higher than the untreated group. The highest average MOE was $15.7 \mathrm{GPa}$ for the $3 \%$ group, which was $140.5 \%$ higher than the untreated group.

When the treatment time ranged from 12 to $36 \mathrm{~h}$, the average MOE ranged from 12.0 to $16.2 \mathrm{GPa}$, which caused a coefficient of variance of $15.1 \%$. The average MOE values of the 12-, 24-, and 36-h groups were all higher than the untreated group. The highest average MOE was $16.2 \mathrm{GPa}$ for the 24 -h group, which was $148.9 \%$ higher than the untreated group.

The results of the coefficient of variance analysis indicated that the treatment time had a greater effect on the MOE than the alkali concentration. The analysis of variance indicated that the effects of the alkali concentration and the treatment time were both significant at a 0.05 level. Among the nine treated groups, the highest MOE was $17.9 \mathrm{GPa}$ for A3, which was $173.7 \%$ higher than the untreated group.

\section{Effects of the alkali treatment on the WSS of the composites}

Table 9 shows the WSS of the composites made from the alkali-treated veneers. The WSS values of A2, A3, A5, and A7 were higher than the untreated group. The average WSS of the treated groups was $0.65 \mathrm{MPa}$, which was $12.3 \%$ lower than the untreated group.

When the alkali concentration ranged from $3 \%$ to $11 \%$, the average WSS ranged from 0.55 to $0.70 \mathrm{MPa}$, which caused a coefficient of variance of $12.8 \%$. The average WSS values of the $3 \%, 7 \%$, and $11 \%$ groups were all lower than the untreated group. The highest average WSS was $0.70 \mathrm{MPa}$ for the $7 \%$ group, which was $5.4 \%$ lower than the untreated group. 
Table 9. WSS (MPa) of the Alkali-Treated Composites (A1 to A9)

\begin{tabular}{|c|c|c|c|c|}
\hline \multirow{2}{*}{$\begin{array}{l}\text { Treatment Time } \\
\text { (h) }\end{array}$} & \multicolumn{3}{|c|}{ Alkali Concentration (\%) } & \multirow{2}{*}{ Average } \\
\hline & 3 & 7 & 11 & \\
\hline 12 & $\begin{array}{c}0.39 \\
(0.04)\end{array}$ & $\begin{array}{c}0.44 \\
(0.03)\end{array}$ & $\begin{array}{c}0.88 \\
(0.03)\end{array}$ & $\begin{array}{c}0.57 \\
(0.27)\end{array}$ \\
\hline 24 & $\begin{array}{c}0.76 \\
(0.04)\end{array}$ & $\begin{array}{c}0.96 \\
(0.10)\end{array}$ & $\begin{array}{c}0.40 \\
(0.03)\end{array}$ & $\begin{array}{c}0.71 \\
(0.28) \\
\end{array}$ \\
\hline 36 & $\begin{array}{c}0.93 \\
(0.05)\end{array}$ & $\begin{array}{c}0.70 \\
(0.02)\end{array}$ & $\begin{array}{c}0.38 \\
(0.02)\end{array}$ & $\begin{array}{c}0.67 \\
(0.28) \\
\end{array}$ \\
\hline Average & $\begin{array}{c}0.69 \\
(0.28)\end{array}$ & $\begin{array}{c}0.70 \\
(0.26)\end{array}$ & $\begin{array}{c}0.55 \\
(0.28)\end{array}$ & $\begin{array}{c}0.65 \\
(0.25)\end{array}$ \\
\hline
\end{tabular}

When the treatment time ranged from 12 to $36 \mathrm{~h}$, the average WSS ranged from 0.57 to $0.71 \mathrm{MPa}$, which caused a coefficient of variance of $10.9 \%$. The average WSS values of the 12-, 24-, and 36-h groups were all lower than the untreated group. The highest average WSS was $0.71 \mathrm{MPa}$ for the 24-h group, which was $4.5 \%$ lower for than the untreated group.

The results of the coefficient of variance analysis indicated that the alkali concentration had a greater effect on the WSS than the treatment time. The analysis of variance indicated that the effects of the alkali concentration and the treatment time were both insignificant at a 0.05 level. Among the nine treated groups, the highest WSS was $0.96 \mathrm{MPa}$ for A5, which was $29.7 \%$ higher than the untreated group.

\section{Discussion of the effects of the alkali treatment on the wood and composites}

Alkali treatment of natural fibers changes their chemical composition by selectively dissolving cell wall compounds, such as hemicellulose, cellulose, and lignin. For example, Ndazi et al. (2008) reported that $\mathrm{NaOH}$ treatment of rice husk decreased the proportion of hemicellulose and lignin. Ray et al. (2009) reported that $\mathrm{NaOH}$ treatment of jute fibers led to a closer packing of cellulose chains and increased the crystallinity. Elenga et al. (2013) studied $\mathrm{NaOH}$-treated Raffia textilis fibers, and noted that hemicellulose and lignin were amorphous components that separated the parallel crystallites in fibers. These components were dissolved during the alkali treatment. This enabled some of the crystallites to join by intermolecular hydrogen bonding, which could increase the crystallinity index. With high $\mathrm{NaOH}$ concentrations or long treatment times, the sodium ions could penetrate and swell the crystallites, which could dissolve less ordered crystallites, and thus decrease the crystallinity index. The swelling of crystallites was pointed out to be the beginning of the polymorphic transformation from cellulose I to cellulose II. Lazim et al. (2014) reported that $\mathrm{NaOH}$ treatment increased the cellulose content of betel nut husk fibers, but partially extracted hemicellulose and lignin, which acted as binder substances to cement microfibrils together. Moreover, the alkali treatment changed the crystallinity of the cellulosic molecular structures, which was attributed to the partial conversion of cellulose I into cellulose II, and generated more amorphous cellulose structures with low mechanical properties. Then et al. (2014) reported that $\mathrm{NaOH}$ treatment of oil palm mesocarp fibers removed the surface wax, hemicellulose, and lignin from the fibers. Gao et al. (2014) reported that $\mathrm{NaOH}$ treatment of kraft fibers led to the destruction of the cellulose crystalline area through the penetration of sodium ions, which decreased the degree of crystallinity. Lu et al. (2014) reported that $\mathrm{NaOH}$ treatment of bamboo cellulose fibers did 
not introduce new functional groups to the cellulose structure, but the hydrogen-bond interaction that connected the cellulose and impurities was disturbed. The treatment did not change the crystalline structure of the fibers, but increased the crystallinity because the impurities with lower crystallinities were dissolved by the $\mathrm{NaOH}$ solution and removed from the fibers, which increased the mechanical properties of the fiber itself. Cao et al. (2017) reported that $\mathrm{NaOH}$ and $\mathrm{NH}_{3} \cdot \mathrm{H}_{2} \mathrm{O}$ treatments of wheat straw increased the crystallinity. Elenga et al. (2013) mentioned that the reaction between $\mathrm{NaOH}$ and the hydroxyl group in cellulose was as follows:

$$
\text { Fiber }-\mathrm{OH}+\mathrm{NaOH} \rightarrow \text { Fiber }-\mathrm{O}-\mathrm{Na}^{+}+\mathrm{H}_{2} \mathrm{O}
$$

The above-mentioned chemical transformations can affect the properties of natural fibers. For example, Ray et al. (2009) reported that $\mathrm{NaOH}$ treatment of jute fibers led to several changes in the fine structure, such as fiber fibrillation and the creation of voids. Lu et al. (2014) studied $\mathrm{NaOH}$-treated bamboo cellulose fibers, and found that the surface of the untreated fibers was mostly covered with amorphous cellulose and/or impurities. After the alkali treatment, the cellulosic microfibers displayed a neat and ordered surface because of the removal of impurities, and the wrinkled surface of the treated fibers increased the surface area. Then et al. (2014) reported that $\mathrm{NaOH}$ treatment of oil palm mesocarp fibers produced a rough surface morphology. Daud et al. (2017) reported that $\mathrm{NaOH}$ treatment of palm kernel shells removed hemicellulose and lignin, which increased the surface roughness of the fibers. Elenga et al. (2013) reported that $\mathrm{NaOH}$-treated $R$. textilis fibers had a clean and smooth surface, and exhibited enhanced tensile strength, but decreased Young's modulus. Lazim et al. (2014) reported that $\mathrm{NaOH}$ treatment of betel nut husk fibers decreased the tensile strength and Young's modulus of the fibers. This was ascribed to the damages in the fiber structures, such as cell wall thinning and deep pores in the fibers caused by the alkali treatment. Moreover, the decreased mechanical properties were also attributed to changes in the cellulose crystallinity index, which was because of the formation of more cellulose II with low mechanical properties. Elenga et al. (2013) described the reaction kinetics for the $\mathrm{NaOH}$ treatment of lignocellulosic fibers, and found that low $\mathrm{NaOH}$ concentrations or short treatment times could partially dissolve the matrix of fibers (hemicellulose, pectin, and lignin). This dissolution resulted in a better alignment of fibrils, but reduced the stiffness of the fibers, which increased the strength of the fibers, but decreased the modulus. However, excessive alkali treatment could destroy the matrix and attack the cellulosic fibrils, which would result in fiber weakening.

According to the above analysis on natural fibers, the alkali treatment may produce some positive effects on the mechanical properties of the eucalyptus veneer/HDPE film composites. For example, the alkali treatment could remove hydrophilic hemicellulose, which could reduce the hydrophilicity of veneer surfaces, and enhance compatibility with HDPE films, which would improve the interfacial adhesion of the composites. Additionally, the alkali treatment could increase the surface roughness and surface area of veneers, which could provide more efficient contact with the HDPE films. This would strengthen the adhesive bonded joints in the composites. Furthermore, a moderate alkali treatment could improve the mechanical properties of wood, which might be beneficial for the mechanical properties of the composites. In this research, the positive effects of the alkali treatment were observed. For example, as shown in Tables 7 to 9, the MOR, MOE, and WSS values of most of the treated groups were higher than the untreated group. 
Similar results were found in previous studies on natural fiber composites. For example, Kalagar et al. (2011) reported that a $5 \% \mathrm{NaOH}$ treatment of rice straw flour increased the flexural strength and modulus, and tensile strength and modulus of fiber/polypropylene composites. Lu et al. (2014) reported that $\mathrm{NaOH}$ treatment of bamboo cellulose fibers improved the tensile strength and Young's modulus of fiber/poly(lactic acid) composites. Then et al. (2014) reported that $\mathrm{NaOH}$ treatment of oil palm mesocarp fibers increased the tensile strength and modulus of fiber/poly(butylene succinate) composites, and decreased the water absorption and thickness swelling. Daud et al. (2017) reported that $\mathrm{NaOH}$ treatment of palm kernel shells increased the tensile strength of fiber/natural rubber composites.

It should be noted that alkali treatment may also produce some negative effects on natural fibers or wood. For example, excessive treatment could wreck the matrix and cellulosic fibrils, which would decrease the mechanical properties of the fibers. That might be not beneficial for the mechanical properties of the eucalyptus veneer/HDPE film composites. In this research, negative effects from the alkali treatment were also observed. For example, as shown in Tables 7 to 9, when the treatment time was $36 \mathrm{~h}$, the MOR, MOE, and WSS values all decreased when the alkali concentration increased from $3 \%$ to $11 \%$. Similar results were found in previous studies on natural fiber composites. For example, Kalagar et al. (2011) reported that a $10 \% \mathrm{NaOH}$ treatment of rice straw flour decreased the tensile modulus of fiber/polypropylene composites. Gao et al. (2014) reported that $\mathrm{NaOH}$ treatment of kraft fibers decreased the tensile strength of fiber/unsaturated polyester composites. Daud et al. (2017) reported that $\mathrm{NaOH}$ treatment of palm kernel shells decreased the tensile modulus of fiber/natural rubber composites.

In this research, both positive and negative effects from the alkali treatment on the eucalyptus veneer/HDPE film composites were observed, which indicated that they were two competing factors with complicated interactions. The effect that was dominant depended on the treatment conditions (alkali concentration and treatment time). Elenga et al. (2013) noted that the evolution of the mechanical properties for alkali-treated natural fibers was difficult to predict. For example, the dissolution of cementing components (hemicellulose and lignin) could decrease the fiber stiffness, but the increase in cellulose crystallinity and orientation could counterbalance this decrease. Therefore, the effect of alkali treatment on the properties of plywood composites might also be difficult to predict. Similar to the heat treatment, the general optimum conditions of the alkali treatment for the MOR, MOE, and WSS were not found, which indicated that the effects of the alkali treatment on the three properties were different.

\section{Determination of the optimum conditions for the alkali treatment}

Similar to the analysis for the Table 6 data for the heat treatment, the optimum conditions for the alkali treatment were also determined according to the variation ratios of the mechanical data for the treated groups compared with the untreated group.

Table 10 shows the variation ratios of the MOR, MOE, and WSS for A1 to A9 compared with the untreated group. As can be seen, the WSS variation ratios for A1, A4, A6, A8, and A9 were negative, and so these groups were not considered to be the optimum conditions for the alkali treatment. The average variation ratios for A2 and A3 were remarkably higher than A5 and A7, but the WSS variation ratio of A2 was very low (only $2.70 \%$ ). Thus, A3 was determined to be the optimum conditions for the alkali treatment. 
Table 10. Variation Ratios of the MOR, MOE, and WSS of the Composites

\begin{tabular}{|c|c|c|c|c|}
\hline \multirow{2}{*}{ Group Number } & \multicolumn{4}{|c|}{ Variation Ratio Compared with the Untreated Group (\%) } \\
\cline { 2 - 5 } & MOR & MOE & WSS & Average \\
\hline A1 & 72.44 & 75.27 & -47.30 & 33.47 \\
\hline A2 & 251.59 & 172.36 & 2.70 & 142.22 \\
\hline A3 & 267.51 & 173.74 & 25.68 & 155.64 \\
\hline A4 & 79.88 & 72.08 & -40.54 & 37.14 \\
\hline A5 & 141.35 & 168.03 & 29.73 & 113.03 \\
\hline A6 & 211.45 & 132.37 & -5.41 & 112.81 \\
\hline A7 & 100.99 & 104.26 & 18.92 & 74.72 \\
\hline A8 & 110.18 & 106.35 & -45.95 & 56.86 \\
\hline A9 & 88.62 & 82.73 & -48.65 & 40.90 \\
\hline
\end{tabular}

\section{Effects of the Heat and Alkali Treatments on the Microscopic Morphologies of the Veneer Surfaces}

Figure 1 shows the SEM images of the untreated, heat-treated, and alkali-treated eucalyptus veneer surfaces. Compared with the untreated group (Fig. 1a), the veneer surfaces at both the heat-treated group (Fig. 1b) and alkali-treated group (Fig. 1d) were relatively coarse and porous. Under a greater magnification, the cracks and pores on the treated veneer surfaces can be seen more clearly in Fig. 1c and 1e. Similar results for other wood species and natural fibers were found in previous research. For example, Chu et al. (2016) reported the morphological properties of the heat-treated poplar wood. They found that the treated wood showed a more open structure with distinctly increased size and number of pores, visible changes in pitting, and residual degradation products around the pores; additionally, the treated wood also presented stratified microstructures and some deformation of libriform fibers near the vessels. They noted that these microstructural changes of the heat-treated wood might be explained by the degradation of cellular wall components, as well as vapor pressure during the heat modification. Daud et al. (2017) reported the morphological properties of the alkali-treated palm kernel shell particles. They found that the raw particles had various smooth shapes, and dirt and impurities were present. The rough surfaces of the treated particles were apparent, with evidence of cementing material being removed after the alkali treatment; besides, pores were also seen on the surfaces of the treated particles, indicating exposed lumens as the result of the alkali treatment. They explained that lignin and hemicellulose, which provide a non-crystalline structure for the plant fiber, were removed by the alkali treatment.

After the heat and alkali treatments, the effects of the morphological variation of the natural fibers on their composites were analyzed by some researchers. For example, Fang et al. (2017) reported the HDPE film-bonded plywood made from the heat-treated poplar veneer. They interpreted that the compatibility of the poplar veneer and HDPE film was improved under thermal treatment; this was achieved by increasing the ability of HDPE molecules to fill the small cavities on the veneer to form mechanical interlock. Ahamad Nordin et al. (2017) reported the heat-treated oil palm mesocarp fiber/ polypropylene composites. They pointed out that the heat treatment gave rougher surface topography of the fiber, consequently increasing the effective surface area to which polypropylene could adhere on the fiber surface, thus some treated composites had higher 
mechanical properties compared with the untreated group. However, the disruption of fiber structure when treated at high temperature affected the strength of the fiber and hence led to the reduction of mechanical properties for some treated composites.

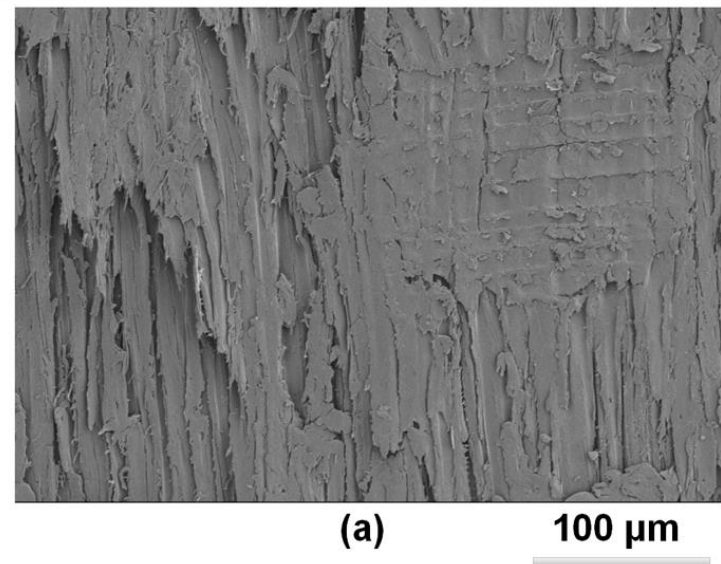

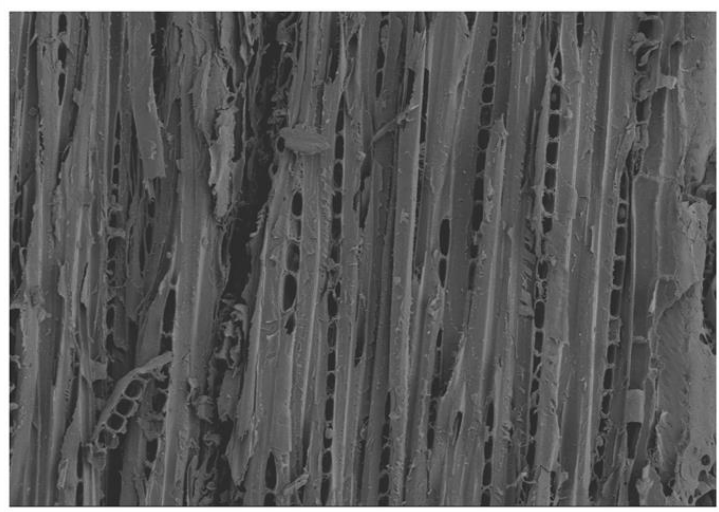

(b) $200 \mu \mathrm{m}$

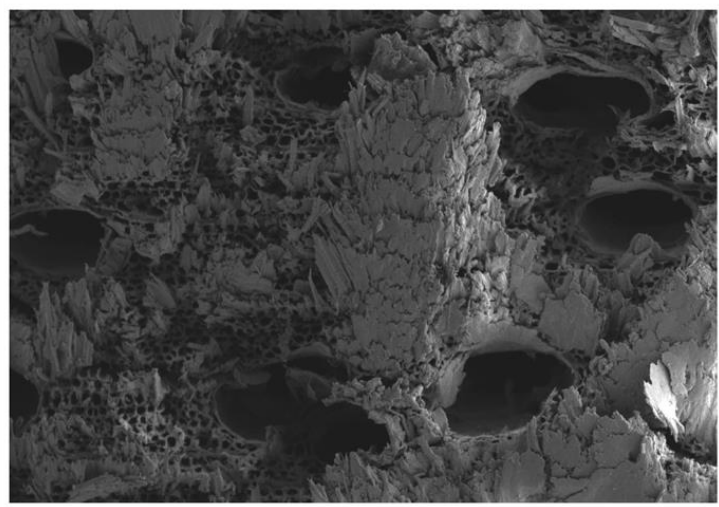

(d)
$300 \mu \mathrm{m}$

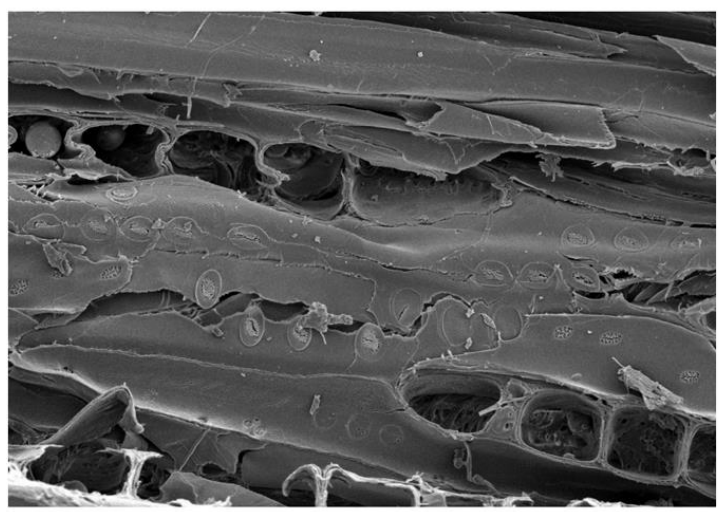

(c)

$50 \mu \mathrm{m}$

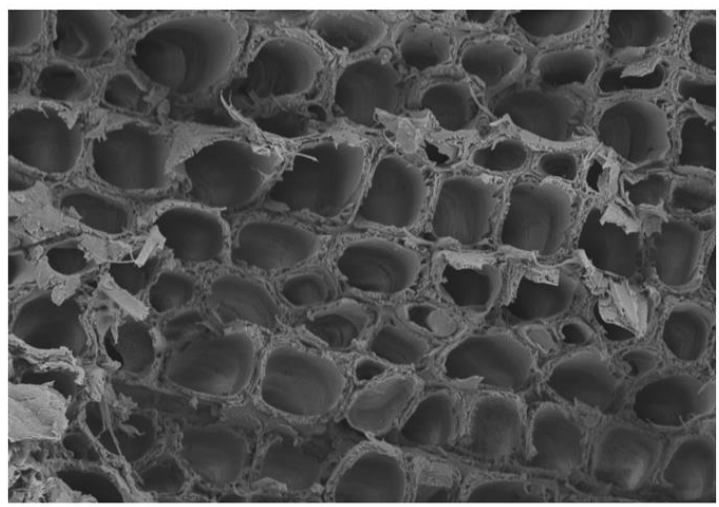

(e)
$50 \mu \mathrm{m}$

Fig. 1. SEM images of the (a) untreated veneer surfaces, ( $b$ and $c$ ) heat-treated veneer surfaces of $\mathrm{H} 16$, and $(\mathrm{d}$ and $\mathrm{e})$ alkali-treated veneer surfaces of $\mathrm{A} 9$

Lazim et al. (2014) reported the alkali-treated waste betel nut husk fiber/vinyl ester resin composites. They remarked that the alkali treatment created rougher surface and deeper pores on fiber surface, which increased the effective surface area that was possible 
for adhesion with the matrix resin, and provided more anchoring points for interfacial bonding between fiber and polymer matrix via mechanical interlocking mechanisms. Daud et al. (2017) reported the alkali-treated palm kernel shell particle/natural rubber composites. They mentioned that the stiffness of some treated composites decreased because of the removal of lignin and hemicellulose from the filler. Lignin acts as a cementing medium that provides toughness to the natural filler. Thus, an increase in the delignification of filler might reduce the moduli of the composites. The above discussion indicated that, after the heat and alkali treatments, the morphological variation of the natural fibers had both positive and negative effects on their composites. This conclusion was consistent with the experimental data found in this research. For example, the eucalyptus veneer/HDPE film composites made from the heat-treated veneers (H16) and alkali-treated veneers (A9) exhibited a higher MOR and MOE but a lower WSS compared with the untreated group.

This research preliminarily demonstrated the positive effects of the heat and alkali treatments on some of the mechanical properties of eucalyptus veneer/HDPE film composites. In future works, the effect on other properties of the composites, such as the water resistance and thermal stability, can be further investigated. Additionally, some surface properties, such as the surface chemistry and surface wettability, of the veneers can also be examined to achieve a better understanding of the effects of these treatments.

\section{CONCLUSIONS}

1. Both the heat and alkali treatments of the veneers improved the mechanical properties of the eucalyptus veneer/HDPE film plywood composites.

2. The heat treatment was better at improving the WSS of the composites, while the alkali treatment was better at improving the MOR and MOE of the composites.

3. For the heat treatment, the highest MOR, MOE, and WSS values of the composites were observed for $\mathrm{H} 7, \mathrm{H} 9$, and $\mathrm{H} 10$ and $\mathrm{H} 12$, respectively, and were $65.6 \%, 65.8 \%$, and $81.1 \%$ higher than the untreated group, respectively.

4. The optimum conditions for the heat treatment were determined to be the H10 conditions, which caused increases of $30.6 \%, 47.1 \%$, and $81.1 \%$ to the MOR, MOE, and WSS of the composites, respectively.

5. For the alkali treatment, the highest MOR, MOE, and WSS values of the composites were observed for A3, A3, and A5, respectively, and were $267.5 \%, 173.7 \%$, and $29.7 \%$ higher than the untreated group, respectively.

6. The optimum conditions for the alkali treatment was determined to be the A3 conditions, which caused increases of $267.5 \%, 173.7 \%$, and $25.7 \%$ to the MOR, MOE, and WSS of the composites, respectively.

7. Compared with the untreated group, the SEM images indicated that both the heat- and alkali-treated veneer surfaces had a more open structure with remarkably increased numbers and sizes of pores and cracks. 


\section{ACKNOWLEDGMENTS}

This research was supported by the National Natural Science Foundation of China (31670571), Beijing Natural Science Foundation (6162019), National Key R \& D Program of China (2017YFD0600804), Co-built Foundation with Beijing Municipal Education Commission " $\mathrm{R} \&$ D on Key Technology in Scientific Utilization of Non-wood Plant Raw Materials" (2016GJ-01), Co-built Foundation with Zhejiang Province "R \& D on Natural Fiber Composites and Environmentally Friendly Adhesives" (CZXC201410), and the Fundamental Research Funds for the Central Universities of China. The authors are also grateful for the technical support from the Chinese Academy of Forestry, Zhejiang Chengzhu Advanced Material Technology Co. Ltd., Anhui Sentai WPC Group Co. Ltd, and Mr. Zaihua Shen.

\section{REFERENCES CITED}

Ahamad Nordin, N. I. A., Ariffin, H., Hassan, M. A., Shirai, Y., Ando, Y., Ibrahim, N. A., and Wan Yunus, W. M. Z. (2017). "Superheated steam treatment of oil palm mesocarp fiber improved the properties of fiber-polypropylene biocomposite," BioResources 12(1), 68-81. DOI: 10.15376/biores.12.1.68-81

Ayata, U., Gurleyen, L., Esteves, B., Gurleyen, T., and Cakicier, N. (2017). "Effect of heat treatment (ThermoWood) on some surface properties of parquet beech (Fagus orientalis Lipsky.) with different layers of UV system applied," BioResources 12(2), 3876-3889. DOI: 10.15376/biores.12.2.3876-3889

Cao, Y., Song, W., Yang, Z., Chen, Z., and Zhang, S. (2017). "The properties of particleboard made from alkaline-treated wheat straw and methylene diphenyl diisocyanate binder," BioResources 12(2), 3265-3276. DOI: 10.15376/biores.12.2.3265-3276

Chang, L., Tang, Q., Gao, L., Fang, L., Wang, Z., and Guo, W. (2016). "Fabrication and characterization of HDPE resins as adhesives in plywood," European Journal of Wood and Wood Products, 1-11.

Chang, L., Guo, W., and Tang, Q. (2017). “Assessing the tensile shear strength and interfacial bonding mechanism of poplar plywood with high-density polyethylene films as adhesive," BioResources 12(1), 571-585. DOI: 10.15376/biores.12.1.571-585

Chu, D., Xue, L., Zhang, Y., Kang, L., and Mu, J. (2016). "Surface characteristics of poplar wood with high-temperature heat treatment: Wettability and surface brittleness," BioResources 11(3), 6948-6967. DOI: 10.15376/biores.11.3.6948-6967

Daud, S., Ismail, H., and Abu Bakar, A. (2017). "A study on the curing characteristics, tensile, fatigue, and morphological properties of alkali-treated palm kernel shell-filled natural rubber composites," BioResources 12(1), 1273-1287. DOI: 10.15376/biores.12.1.1273-1287

Di, M., Wang, S., and Yao, Z. (2017). "Research progress in the lignin-based formaldehyde-free wood adhesives," Journal of Forestry Engineering 2(1), 8-14. DOI: 10.13360/j.issn.2096-1359.2017.01.002

Ding, T., Gu, L., and Cai, J. (2015). "Effects of heat treatment on the moisture adsorption characteristic and dimensional stability of wood," Journal of Nanjing Forestry University (Natural Sciences Edition) 39(2), 143-147. DOI: 10.3969/j.issn.10002006.2015.02.025 
Ding, T., Gu, L., and Liu, X. (2011). "Influence of steam pressure on chemical changes of heat-treated Mongolian pine wood," BioResources 6(2), 1880-1889. DOI: 10.15376/biores.6.2.1880-1889

Ding, T., Wang, C., and Peng, W. (2016). "A theoretical study of moisture sorption behavior of heat-treated pine wood using Raman spectroscopic analysis," Journal of Forestry Engineering 1(5), 15-19. DOI: 10.13360/j.issn.2096-1359.2016.05.003

Du, L., Li, Y., Lee, S., and Wu, Q. (2014). "Water absorption properties of heat-treated bamboo fiber and high density polyethylene composites," BioResources 9(1), 11891200. DOI: 10.15376/biores.9.1.1189-1200

Elenga, R. G., Djemia, P., Tingaud, D., Chauveau, T., Maniongui, J. G., and Dirras, G. (2013). "Effects of alkali treatment on the microstructure, composition, and properties of the Raffia textilis fiber," BioResources 8(2), 2934-2949. DOI: 10.15376/biores.8.2.2934-2949

Esteves, B. M., and Pereira, H. M. (2009). "Wood modification by heat treatment: A review," BioResources 4(1), 370-404. DOI: 10.15376/biores.4.1.370-404

Fang, L., Chang, L., Guo, W.-j., Chen, Y.-p., and Wang, Z. (2013a). "Manufacture of environmentally friendly plywood bonded with plastic film," Forest Prod. J. 63(7-8), 283-287. DOI: 10.13073/FPJ-D-12-00062

Fang, L., Chang, L., Guo, W.-j., Ren, Y.-p., and Wang, Z. (2013b). "Preparation and characterization of wood-plastic plywood bonded with high density polyethylene film," European Journal of Wood and Wood Products 71(6), 739-746. DOI: 10.1007/s00107-013-0733-0

Fang, L., Chang, L., Guo, W.-j., Chen, Y.-p., and Wang, Z. (2014). "Influence of silane surface modification of veneer on interfacial adhesion of wood-plastic plywood," Appl. Surf. Sci. 288, 682-689. DOI: 10.1016/j.apsusc.2013.10.098

Fang, L., Xiong, X., Wang, X., Chen, H., and Mo, X. (2017). "Effects of surface modification methods on mechanical and interfacial properties of high-density polyethylene-bonded wood veneer composites," J. Wood Sci. 63(1), 65-73. DOI: 10.1007/s10086-016-1589-9

Fang, L., Wang, X., Xiong, X., Zou, Y., and Wang, Z. (2016a). "Effects of surface pretreatments on wet cycle resistance of wood-plastic plywood," Journal of Forestry Engineering 1(1), 37-41. DOI: 10.13360/j.issn.2096-1359.2016.01.007

Fang, L., Yin, Y., Han, Y., Chang, L., and Wu, Z. (2016b). "Effects of number of film layers on properties of thermoplastic bonded plywood," Journal of Forestry Engineering 1(6), 45-50. DOI: 10.13360/j.issn.2096-1359.2016.06.008

Fang, L., Wang, Z., Xiong, X., Wang, X., and Wu, Z. (2016c). "Effects of initiator on properties of silane modified poplar veneer/high density polyethylene (HDPE) film composites," Journal of Nanjing Forestry University (Natural Sciences Edition) 40(3), 133-136. DOI: 10.3969/j.issn.1000-2006.2016.03.022

GB/T 9846 (2015). "Plywood for general use," Standardization Administration of China, Beijing, China.

Gao, Z., Di, M., Zhang, X., and Zhang, D. (2014). "Effects of alkali treatment and polyisocyanate crosslinking on the mechanical properties of kraft fiber-reinforced unsaturated polyester composites," BioResources 9(4), 5906-5916. DOI: 10.15376/biores.9.4.5906-5916

Kalagar, M., Khademieslam, H., Bazyar, B., and Hejazi, S. (2011). "Morphology and mechanical properties of alkali-treated rice straw flour-polypropylene composites," BioResources 6(4), 4238-4246. DOI: 10.15376/biores.6.4.4238-4246 
Lazim, Y., Salit, S. M., Zainudin, E. S., Mustapha, M., and Jawaid, M. (2014). "Effect of alkali treatment on the physical, mechanical, and morphological properties of waste betel nut (Areca catechu) husk fibre," BioResources 9(4), 7721-7736. DOI: 10.15376/biores.9.4.7721-7736

Li, Y., Du, L., Kai, C., Huang, R., and Wu, Q. (2013). "Bamboo and high density polyethylene composite with heat-treated bamboo fiber: Thermal decomposition properties," BioResources 8(1), 900-912. DOI: 10.15376/biores.8.1.900-912

Li, Y., Du, L., Zhang, Z., and Wu, Q. (2015). "High-density polyethylene and heattreated bamboo fiber composites: Nonisothermal crystallization properties," International Journal of Polymer Science 2015. DOI: 10.1155/2015/658584

Lu, T., Liu, S., Jiang, M., Xu, X., Wang, Y., Wang, Z., Gou, J., Hui, D., and Zhou, Z. (2014). "Effects of modifications of bamboo cellulose fibers on the improved mechanical properties of cellulose reinforced poly(lactic acid) composites," Compos. Part B-Eng. 62, 191-197. DOI: 10.1016/j.compositesb.2014.02.030

Missio, A. L., de Cademartori, P. H. G., Mattos, B. D., Santini, E. J., Haselein, C. R., and Gatto, D. A. (2016). "Physical and mechanical properties of fast-growing wood subjected to freeze-heat treatments," BioResources 11(4), 10378-10390. DOI: 10.15376/biores.11.4.10378-10390

Ndazi, B. S., Nyahumwa, C., and Tesha, J. (2008). "Chemical and thermal stability of rice husks against alkali treatment," BioResources 3(4), 1267-1277. DOI: 10.15376/biores.3.4.1267-1277

Qi, C., Li, K., Zhao, B., Yang, S., Li, S., and Zhou, M. (2016). "Effects of high density polyethylene content and distribution on properties of oriented strand and plastic board," Journal of Forestry Engineering 1(6), 39-44. DOI: 10.13360/j.issn.20961359.2016.06.007

Ray, D., Das, M., and Mitra, D. (2009). "Influence of alkali treatment on creep properties and crystallinity of jute fibres," BioResources 4(2), 730-739. DOI: 10.15376/biores.4.2.730-739

Song, W., Cao, Y., Wang, D., Hou, G., Shen, Z., and Zhang, S. (2015a). “An investigation on formaldehyde emission characteristics of wood building materials in Chinese standard tests: Product emission levels, measurement uncertainties, and data correlations between various tests," PLoS ONE 10(12). DOI:

10.1371/journal.pone.0144374

Song, W., Zhao, F., Yu, X., Wang, C., Wei, W., and Zhang, S. (2015b). "Interfacial characterization and optimal preparation of novel bamboo plastic composite engineering materials," BioResources 10(3), 5049-5070. DOI: 10.15376/biores.10.3.5049-5070

Song, W., Wei, W., Ren, C., and Zhang, S. (2016). "Developing and evaluating composites based on plantation eucalyptus rotary-cut veneer and high-density polyethylene film as novel building materials," BioResources 11(2), 3318-3331. DOI: 10.15376/biores.11.2.3318-3331

Song, W., Wei, W., Li, X., and Zhang, S. (2017a). "Utilization of polypropylene film as an adhesive to prepare formaldehyde-free, weather-resistant plywood-like composites: Process optimization, performance evaluation, and interface modification," BioResources 12(1), 228-254. DOI: 10.15376/biores.12.1.228-254

Song, W., Wei, W., Wang, D., and Zhang, S. (2017b). "Preparation and properties of new plywood composites made from surface modified veneers and polyvinyl chloride films," BioResources 12(4), 8320-8339. DOI: 10.15376/biores.12.4.8320-8339 
Then, Y. Y., Ibrahim, N. A., Zainuddin, N., Ariffin, H., Wan Yunus, W. M. Z., and Chieng, B. W. (2015). "Static mechanical, interfacial, and water absorption behaviors of alkali treated oil palm mesocarp fiber reinforced poly(butylene succinate) biocomposites," BioResources 10(1), 123-136. DOI: 10.15376/biores.10.1.123-136

Tufan, M., Güleç, T., Peşman, E., and Ayrilmis, N. (2016). "Technological and thermal properties of thermoplastic composites filled with heat-treated alder wood," BioResources 11(2), 3153-3164. DOI: 10.15376/biores.11.2.3153-3164

Xu, X., Yang, X., Lyu, J., Chen, L., Sun, Y., and Xu, S. (2016). "Dynamic mechanical characteristics of poplar veneers painted with damping coatings," Journal of Nanjing Forestry University (Natural Sciences Edition) 40(4), 125-130. DOI: 10.3969/j.issn.1000-2006.2016.04.020

Yu, H., Fang, C., Zheng, H., Ma, X., Yang, L., and Wang, H. (2015). "Comparison of the limitation and testing method of formaldehyde emission of plywood according to domestic standards with oversea ones," Journal of Nanjing Forestry University (Natural Sciences Edition) 39(6), 163-168. DOI: 10.3969/j.issn.10002006.2015.06.028

Zhan, J., Cao, J., Gu, J., Zhang, X., Chen, W., Liu, Z., Liu, B., and Ma, H. (2015). "Surface densification and high temperature hydrothermal post treatment of the Abies nephrolepis lumber," Journal of Nanjing Forestry University (Natural Sciences Edition) 39(3), 119-124. DOI: 10.3969/j.issn.1000-2006.2015.03.022

Zhang, T., Tu, D., Peng, C., and Zhang, X. (2015). "Effects of heat treatment on physical-mechanical properties of Eucalyptus regnans," BioResources 10(2), 35313540. DOI: 10.15376/biores.10.2.3531-3540

Zhang, Y., Xu, D., Ma, L., Wang, S., and Liu, X. (2017). "Influence of heat treatment on the water uptake behavior of wood," BioResources 12(1), 1697-1705. DOI: 10.15376/biores.12.1.1697-1705

Article submitted: June 1, 2017; Peer review completed: August 4, 2017; Revised version received and accepted: September 15, 2017; Published: October 2, 2017.

DOI: $10.15376 /$ biores.12.4.8683-8703 